\title{
Effectiveness of audiovisual distraction with computerized delivery of anesthesia during the placement of stainless steel crowns in children with Down syndrome
}

\author{
Kausar Sadia Fakhruddin ${ }^{1}$, Hisham El Batawi ${ }^{1}$, M. O. Gorduysus ${ }^{1,2}$
}

Correspondence: Dr. Kausar Sadia Fakhruddin

'Department of Preventive and Restorative Dentistry, College of Dental Medicine, University of Sharjah, Sharjah, United Arab Emirates,

Email: kfakhruddin@sharjah.ac.ae

2Department of Endodontics, Faculty of Dentistry, Hacettepe University, Ankara, Turkiye

\section{ABSTRACT}

Objective: Assessing effectiveness of audiovisual (AV) distraction with/without video eyewear and computerized delivery system-intrasulcular (CDS-IS) for local anesthesia during placement of stainless steel crowns for the management of pathological tooth grinding in children with Down syndrome. Materials and Methods: This clinical study includes 22 children (13 boys and 9 girls), with mean age being 7.1 years. The study involved three sessions 1-week apart. During Session I, dental prophylaxis to the upper jaw was done while watching a movie projected on the ceiling without video eyewear whereas prophylaxis for the lower jaw and impressions of both jaws were taken while watching another movie using eyewear projection. After 1 week, during Session II/III, children had their upper and lower second primary molars which were prepared and steel crowns inserted, respectively, while watching movies which were projected using video eyewear under the effect of CDS-IS local anesthesia. Changes in pulse oximeter and heart rate were recorded every 5 min. Independent sample $t$-test was used to assess significance of changes during each visit. Results: A statistically significant difference $(P<0.03)$ was observed in mean pulse rate between dental prophylaxis without video eyewear and during dental prophylaxis and dental impression taken while children were distracted using AV distracter with video eyewear. We observed an increase in mean pulse rate during tooth preparation use dental drills, but this does not lead to disruptive behavior as children were being distracted by AV distracter with video eyewear. Conclusion: Routine psychological (Tell-Show-Do) intervention along with visual distraction using video eyewear and use of CDS-IS system for anesthetic delivery is recommended as an effective behavior management technique for children with Down syndrome during invasive dental treatment.

Key words: Computerized delivery system-intrasulcular, Down syndrome, pathological tooth grinding, stainless steel crowns, visual distraction video eyewear

\section{INTRODUCTION}

Several studies ${ }^{[1-3]}$ reported that pathological tooth grinding habits are common among mentally challenged children, resulting in severe tooth wear. Down

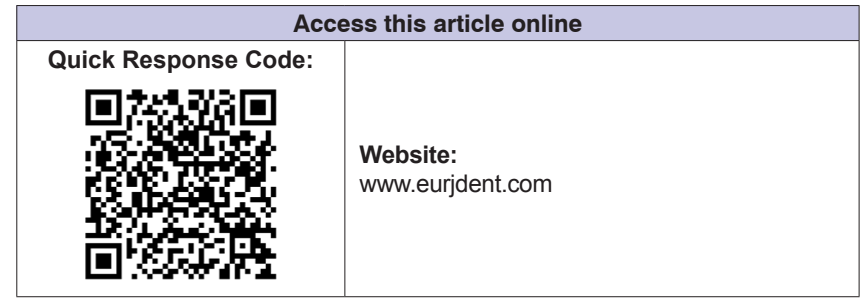

syndrome is a congenital anomaly due to chromosome defect causing intellectual disability. ${ }^{[4]}$ Pathological

This is an open access article distributed under the terms of the Creative Commons Attribution-NonCommercial-ShareAlike 3.0 License, which allows others to remix, tweak, and build upon the work non-commercially, as long as the author is credited and the new creations are licensed under the identical terms.

For reprints contact: reprints@medknow.com

How to cite this article: Fakhruddin KS, El Batawi $\mathrm{H}$, Gorduysus MO. Effectiveness of audiovisual distraction with computerized delivery of anesthesia during the placement of stainless steel crowns in children with Down syndrome. Eur J Dent 2017;11:1-5.

DOI: 10.4103/ejd.ejd_288_16 
tooth grinding in children with Down syndrome is very difficult to manage as behavioral techniques to modify habit or provision of night guards generally gives unsuccessful results. Restoring badly worn teeth with complex restorative work or with prosthetic replacement have shown unsuccessful results due to enlarged hypotonic tongue, immune deficiency, and poor wound healing being common among these children. ${ }^{[1,5,6]}$ The present study aims to assess effectiveness of audiovisual (AV) distraction in combination with computerized delivery of anesthesia (computerized delivery system-intrasulcular [CDS-IS]) during placement of stainless steel crowns for the management of pathological tooth grinding in children with Down syndrome.

\section{MATERIALS AND METHODS}

During routine oral dental examination in Special Needs Teaching Clinic at University Dental Hospital Sharjah, N=22, Children Participated with Down syndrome aged 6-9.5 years were screened. Children were accompanied by their parents/caregivers and were referred from a local center for Down syndrome. The parents were asked to fill the information related to patient's age, general medical conditions, any comorbid factor (seizure), medications, dietary habits, communication skills, and preferences. During dental examination, child's ability to cooperate was also assessed. Under traditional dental setting, 18 children were very cooperative and the examiner was able to record all needed information on their dental charts. However, four children required that the examination be done under oral sedation due to lack of cooperative behavior. During subsequent appointments of these children, oral sedation using phenergan (promethazine, $0.1 \mathrm{mg} / \mathrm{kg}$; maximum $12.5 \mathrm{mg}$ ) was administered before any procedure. This helped relief apprehension and induced easy arousal light sleep. Based on the inclusion criteria as shown in Table 1, children with moderate to severe tooth wear (Group B and C) were recruited. The exclusion criteria included children who were highly uncooperative and needed general anesthesia. Treatment was planned as three appointments or sessions. All treatment sessions were 1 week apart. For the clinical intervention, approval was obtained from the Research Ethics Committee, University of Sharjah, United Arab Emirates.

\section{During session I}

Employing Tell-Show-Do methods of behavior management techniques, graphic animation of dental

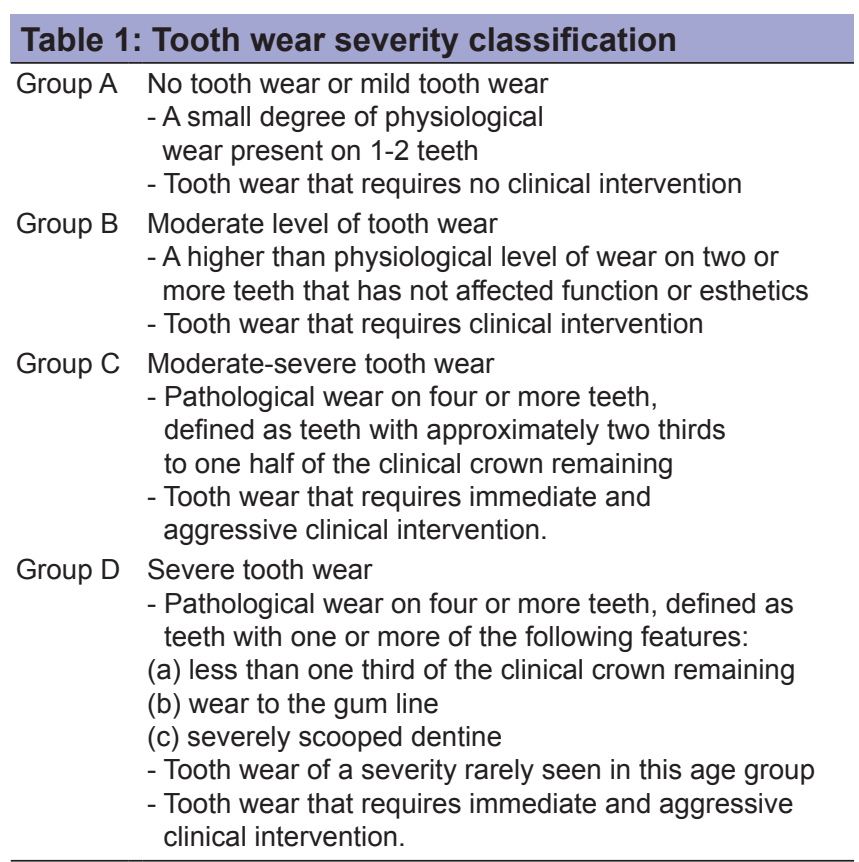

caries and its treatment were shown to these children on iPad (tablet screen). In addition, using dental model, children were introduced and shown how suction, drill, air water syringe feel and work in a playful way. Children were then seated on the dental chair and watched preselected 30 min long, age appropriate cartoon movie from "treehousetv. com" website projected on the ceiling above the dental chair. While they were watching movie, a detailed oral examination was recorded and intraoral radiographs were taken. The same pediatric dentist did the prophylactic cleaning of their upper right and left quadrant using prophy paste and low-speed handpiece.

Then, they were introduced to video eyewear (Vuzix Wrap 310XL; Vuzix Corporation, Rochester, NY, USA) which was connected to the tablet to watch another preselected, $20 \mathrm{~min}$ long movie. However, the same dentist did prophylactic cleaning of their lower right and left quadrant and took dental impressions for the upper and lower jaws using alginate for the study models to save chairside time consumed during crown selection.

For systematic desensitization with vibrations from dental drills, they were given powered toothbrushes (oscillating-rotating type) as a reward for being cooperative during dental procedures. Parents were advised to use these toothbrushes after every meal. 


\section{During session II}

During this session, while the children were watching movie of their choice using video eyewear, pediatric dentist did the prophylactic dental cleaning. Following this, using CDS-IS system, intrasulcular anesthesia was administered. Lower right and left second primary molars were prepared first using high-speed dental drill for placement of stainless steel crowns. The crowns were cemented using glass ionomer cement - fluoride releasing luting cement (SpeedMix ${ }^{\mathrm{TM}}$ syringe, Ultradent Products Inc.,) and the occlusion was assessed.

\section{During session III}

Same as Session II, while these children were watching movie of their choice using video eyewear, the patients were anesthetized by CDS using "single tooth anesthesia machine." Upper right and left second primary molars were prepared. Then, stainless steel crowns were adjusted and cemented on the prepared teeth and occlusions were assessed carefully.

During all the treatment sessions, blood oxygen saturation and pulse rate were monitored and recorded every 5 min using pulse oximeter for approximately $30 \mathrm{~min}$ of tooth preparation and cementation. All the treatment procedures were carried out by one pediatric dentist. An independent sample $t$-test was used to assess the significance of changes during each visit. The statistical significance was set at 0.05 .

\section{RESULTS}

In this clinical study, 22 children with Down syndrome participated ( $n=13$; boy participants and $n=9$ girl participants). Overall, mean age of children was 7.1 years (range, 6.2-9.5 years). The severity of tooth wear was assessed and scored according to the classification criteria listed in Table 1. Almost $19(86 \%)$ children showed signs of tooth wear of different severity levels. There were 7 (32\%) children categorized in Group B, showing moderate level of tooth wear, which requires clinical intervention while $12(55 \%)$ children showing signs of moderate to severe tooth wear were in Group C [Figure 1].

Information obtained from parent's questionnaire showed that $20(91 \%)$ of the parents were aware that their children are engaged in tooth grinding while awake, asleep, or both. Of these children, $6(27 \%)$ children were diurnal grinders, while 11 (50\%) children grind their teeth while asleep, though $3(14 \%)$ children grind their teeth while awake or asleep as

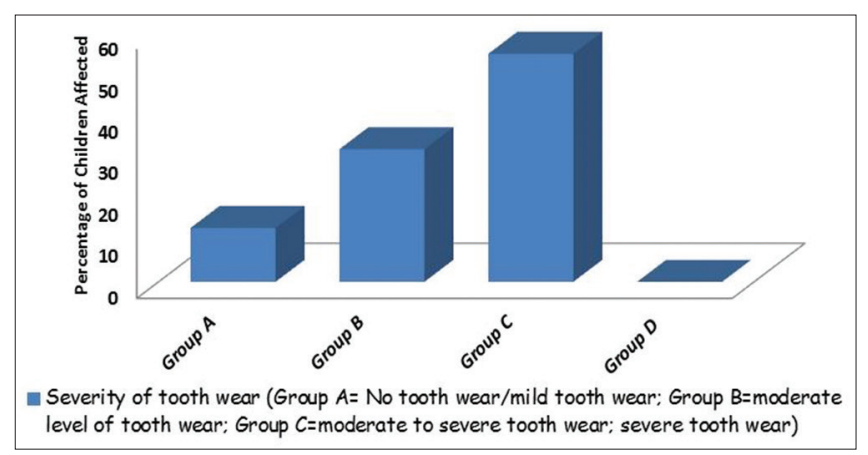

Figure 1: Severity level of tooth wear in children with Down syndrome

reported by their parents [Figure 3]. To the responses related to pain in facial muscle, clicking, or difficulty while opening and closing of mouth in these children, only $5(23 \%)$ parents stated that they had noticed that their children face some difficulty while opening and closing their mouth. However, majority of the parents reported that due to lacking language skills, their children were not able to communicate or express their pain.

During Session I, all the participants watched movie with/without visual eyewear and prophylactic cleaning was done for all the participants. There was a statistically significant difference $(P<0.03)$ observed in mean pulse rate between dental prophylaxis without video eyewear and during dental prophylaxis and dental impression taken while children were distracted using AV distracter with video eyewear.

After 1 week, during Sessions II and III, both treatment groups had undergone tooth preparation and stainless steel crown placements. In our study, we observed increase in mean pulse rate during tooth preparation using dental drills [Figure 2]. However, a reduction in mean pulse rates was observed between Sessions II and III while children were undergoing infiltration using CDS-IS and during tooth preparations although the difference does not represent any statistical significance $(P=0.07)$. There observed no statistically significant difference in oxygen saturation levels between the two sessions [Table 2].

\section{DISCUSSION}

Pathological tooth grinding is often seen in children with underlying neurological disorders such as Down syndrome. ${ }^{[7]}$ Frequency and intensity of tooth grinding sometimes result in extensive enamel loss with wear facets and exposed dentine in the posterior teeth. ${ }^{[1,8]}$ The present study observed extensive tooth 
structure loss in the deciduous teeth clinically and from records obtained from study models. Placement of stainless steel crowns on deciduous molars can help protect permanent teeth and also apt to decrease pathological tooth grinding which may assist in preserving vertical dimension of occlusion. ${ }^{[8]}$ Stainless steel crowns undoubtedly the most durable restoration are inexpensive and can be quickly and easily placed compared to amalgam or composite restorations. ${ }^{[9]}$

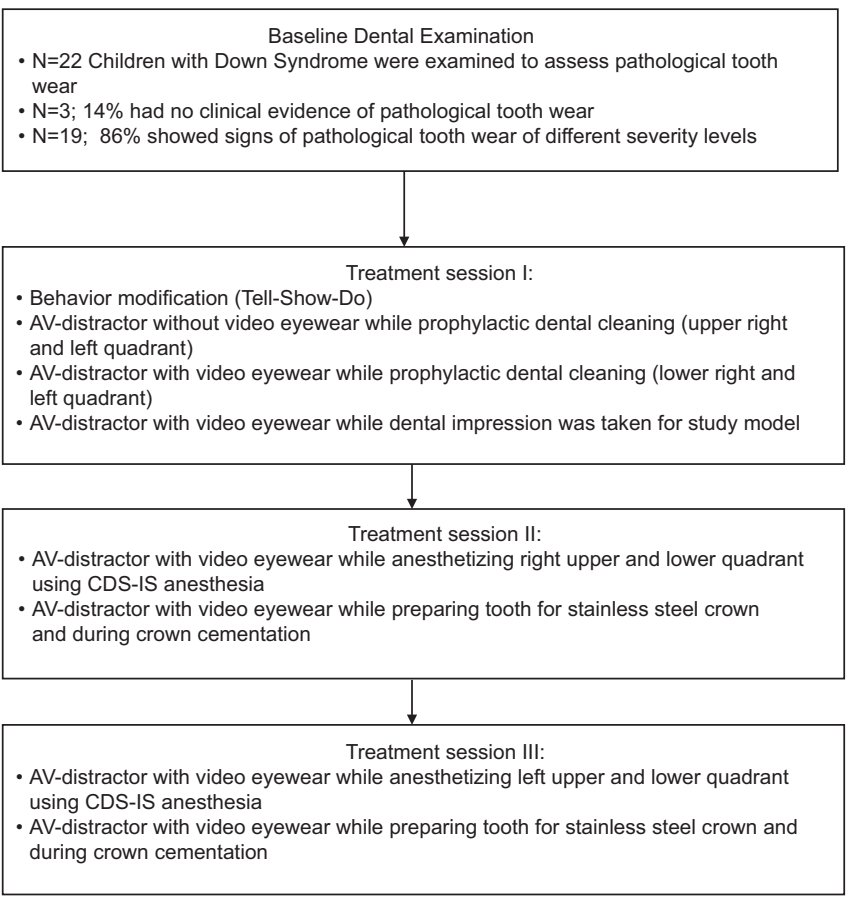

Figure 2: Patient flow through research study
Measuring mesiodistal width, crown length, and height on study model obtained during Session I assisted in appropriate size of crown selection. In addition, evaluation of preoperative occlusion, dental midline, and cusp fossa relationship bilaterally was also done prior to treatment Session II. This reduced chairside time spent on crown selection and adjustments. To introduce and desensitize their visual, auditory, and tactile sensation, in a nonthreatening setting, we demonstrated that using tooth model, how handpiece, suction, air water syringe sound and work. In addition, to explain and demonstrate dental procedure, prophylactic dental cleaning was done during first session, while they were distracted by watching preselected cartoon movies of their choice. This video distraction obtained with video eyewear was to divert their attention away from the feeling of perceived unpleasant procedure and to improve behavior.

Our findings were similar to our previous study which demonstrated that the use of video eyewear may provide better distraction than watching video projected on a screen. As occlusive eyewear projects the images right in front of the eyes of the user, it blocks out real world's visual and auditory stimuli. ${ }^{[10]}$ Thus, through this cognitive behavioral intervention, it helps in diverting attention from a stressful stimulus and focuses it onto a more pleasant one. ${ }^{[11-15]}$

During dental treatment, an effective pain control is important to achieve comfort, cooperation, and compliance in children. ${ }^{[16,17]}$ In our study, we used CDS (Wand, Milestone Scientific, Inc., Deerfield, IL, USA) enabling slow-paced delivery of local anesthetic,

\section{Table 2: Mean changes in pulse oximetry and heart rate}

\begin{tabular}{|c|c|c|c|c|}
\hline & \multicolumn{2}{|c|}{$\begin{array}{l}\text { Change in pulse } \\
\text { oximetry }\end{array}$} & \multicolumn{2}{|c|}{$\begin{array}{l}\text { Change in heart } \\
\text { rate }\end{array}$} \\
\hline & Mean & SD & Mean & SD \\
\hline \multicolumn{5}{|l|}{ Treatment session I } \\
\hline AV distracter without video-eye wear during dental prophylaxis & 3.02 & 1.51 & 5.61 & 1.03 \\
\hline AV distracter with video-eye wear during dental prophylaxis & 2.15 & 1.02 & 2.53 & 1.24 \\
\hline AV distracter with video-eye wear during dental impression & 2.18 & 1.04 & 3.04 & 1.12 \\
\hline$P^{*}$ & \multicolumn{2}{|c|}{0.42} & \multicolumn{2}{|c|}{$0.03^{*}$} \\
\hline \multicolumn{5}{|l|}{ Treatment session II } \\
\hline AV distracter with video-eye wear during anesthesia using CDS-IS system & 3.05 & 1.03 & 3.65 & 1.03 \\
\hline $\begin{array}{l}\text { AV distracter with video-eye wear during tooth } \\
\text { preparation for stainless steel crown }\end{array}$ & 3.12 & 1.16 & 5.83 & 2.02 \\
\hline$P^{*}$ & \multicolumn{2}{|c|}{0.61} & \multicolumn{2}{|c|}{0.53} \\
\hline \multicolumn{5}{|l|}{ Treatment session III } \\
\hline AV distracter with video-eye wear during anesthesia using CDS-IS system & 1.71 & 1.01 & 2.82 & 0.47 \\
\hline $\begin{array}{l}\text { AV distracter with video-eye wear during tooth } \\
\text { preparation for stainless steel crown }\end{array}$ & 2.87 & 0.68 & 4.68 & 0.96 \\
\hline$P^{*}$ & \multicolumn{2}{|c|}{0.43} & \multicolumn{2}{|c|}{0.09} \\
\hline
\end{tabular}




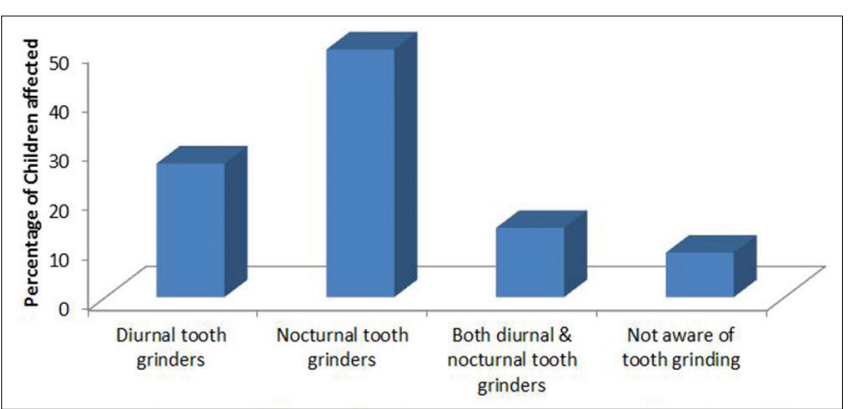

Figure 3: Percentage of children with Down syndrome engaged in pathological tooth grinding habit

in small volume under a controlled low pressure of (165 pound/square inch, psi). Employing CDS-IS system enables operator to control the disadvantages associated with an inferior alveolar block such as pain that affects child's behavior and avoids postoperative self-inflicted injuries (tongue or lip biting) owing to its localized effect and bilateral procedures can be done during single session. ${ }^{[18-22]}$

Vibration and feeling of handpiece during tooth preparation have frequently shown to be the fear-evoking stimuli in children and adults. ${ }^{[23]}$ Similarly, in the present study, we observed an increase in children heart rate during tooth preparation using conventional handpiece. However, AV distraction helped masked the sight of dental procedure and sound of dental drill.

Behavioral modification intervention along with AV distraction and use of CDS-IS system for anesthetic delivery during placement of stainless steel crown is recommended as an effective management technique for treating tooth wear in children with Down syndrome.

We do recognize that children with Down's syndrome exhibit a wide range of cooperation levels on the dental chair and that our study was conducted on a relatively small number of children due to factors related to child availability and wellness to comply with postoperative follow-up care. It is recommended to further investigate the effectiveness of our proposed protocol of management on the cooperation level of such children on a wider scale of children wherever possible.

\section{Financial support and sponsorship}

Nil.

\section{Conflicts of interest}

There are no conflicts of interest.

\section{REFERENCES}

1. Bell EJ, Kaidonis J, Townsend GC. Tooth wear in children with Down syndrome. Aust Dent J 2002;47:30-5.

2. Lindqvist B, Heijbel J. Bruxism in children with brain damage. Acta Odontol Scand 1974;32:313-9.

3. Richmond G, Rugh JD, Dolfi R, Wasilewsky JW. Survey of bruxism in an institutionalized mentally retarded population. Am J Ment Defic 1984;88:418-21

4. Weijerman ME, de Winter JP. Clinical practice. The care of children with Down syndrome. Eur J Pediatr 2010;169:1445-52.

5. Carranza FA, Newman MG, Takei HH, Klokkevold PR. Carranza's Clinical Periodontology. $10^{\text {th }}$ ed. Philadelphia: W.B. Saunders Co.; 2006. p. 299, 397, 409, 623.

6. Dean JA, McDonald RE, Avery DR. Dentistry for the Child and Adolescent. $8^{\text {th }}$ ed. St. Louis, MO: Mosby. p. 164-8, 190-4, 474 .

7. Nishigawa K, Bando E, Nakano M. Quantitative study of bite force during sleep associated bruxism. J Oral Rehabil 2001;28:485-91.

8. Pinkham JR, Casamassimo PS, McTigue DJ, Fields HW Jr., Nowak AJ. Infancy through Adolescence, Pediatric Dentistry. $4^{\text {th }}$ ed. Philadelphia, PA: Elsevier Saunders; 2005.

9. Cameron AC, Widmer RP. Handbook of Pediatric Dentistry. $2^{\text {nd }}$ ed. Mosby: Australasian Academy of Pediatric Dentistry; 2003.

10. Fakhruddin KS, El Batawi H, Gorduysus MO. Effectiveness of audiovisual distraction eyewear and computerized delivery of anesthesia during pulp therapy of primary molars in phobic child patients. Eur J Dent 2015;9:470-5.

11. Bellieni CV, Cordelli DM, Raffaelli M, Ricci B, Morgese G, Buonocore G. Analgesic effect of watching TV during venipuncture. Arch Dis Child 2006;91:1015-7.

12. Hoffman HG, Doctor JN, Patterson DR, Carrougher GJ, Furness TA $3^{\text {rd }}$. Virtual reality as an adjunctive pain control during burn wound care in adolescent patients. Pain 2000;85:305-9.

13. Cassidy KL, Reid GJ, McGrath PJ, Finley GA, Smith DJ, Morley C, et al. Watch needle, watch TV: Audiovisual distraction in preschool immunization. Pain Med 2002;3:108-18.

14. Sparks L. Taking the "ouch" out of injections for children. Using distraction to decrease pain. MCN Am J Matern Child Nurs 2001;26:72-8.

15. Dowling JS. Humor: A coping strategy for pediatric patients. Pediatr Nurs 2002;28:123-31.

16. Berggren U, Meynert G. Dental fear and avoidance: Causes, symptoms, and consequences. J Am Dent Assoc 1984;109:247-51.

17. Jones CM, Heidmann J, Gerrish AC. Children's ratings of dental injection and treatment pain, and the influence of the time taken to administer the injection. Int J Paediatr Dent 1995;5:81-5.

18. Schleder JR, Reader A, Beck M, Meyers WJ. The periodontal ligament injection: A comparison of $2 \%$ lidocaine, $3 \%$ mepivacaine, and $1: 100,000$ epinephrine to $2 \%$ lidocaine with $1: 100,000$ epinephrine in human mandibular premolars. J Endod 1988;14:397-404.

19. Oztas N, Ulusu T, Bodur H, Dogan C. The wand in pulp therapy: An alternative to inferior alveolar nerve block. Quintessence Int 2005;36:559-64.

20. Malamed SF. Sedation: A Guide to Patient Management. $4^{\text {th }}$ ed. St. Louis, MO: CV Mosby Co.; 2003. p. 337.

21. Ran D, Peretz B. Assessing the pain reaction of children receiving periodontal ligament anesthesia using a computerized device (wand). J Clin Pediatr Dent 2003;27:247-50.

22. Ashkenazi M, Blumer S, Eli I. Effectiveness of computerized delivery of intrasulcular anesthetic in primary molars. J Am Dent Assoc 2005;136:1418-25.

23. Aitken JC, Wilson S, Coury D, Moursi AM. The effect of music distraction on pain, anxiety and behavior in pediatric dental patients. Pediatr Dent 2002;24:114-8. 